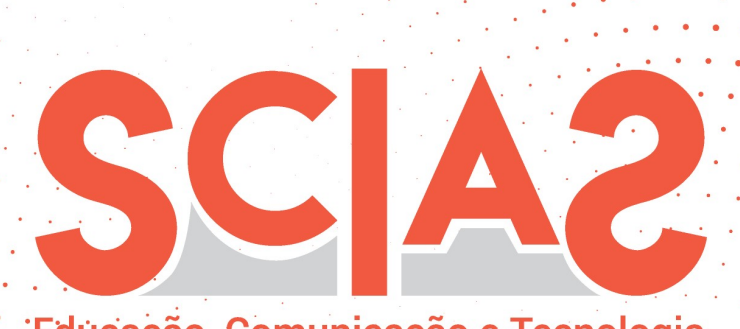

Eduçaçẳo, Comunicação e Tecnologia

Atribuição BB CY 4.0

\title{
Vivências e experiências de uma mãe professora sobre usos da tecnologia em dias de distanciamento social
}

\section{Resumo}

Cislene Gomes Freitas ${ }^{1}$

Este artigo de opinião trata dos dias de uma mulher, mãe, professora e estudante durante o isolamento social e o uso das tecnologias. Neste momento, muitas vezes os papéis se misturam, um precisa se sobrepor ao outro para que as tarefas sejam realizadas com sucesso, mas nem por isso o outro papel se tornou menos importante. Isso gera emoções que precisam ser trabalhadas para que a mulher permaneça inteira e desempenhe todos os papéis que cabem à ela. $\mathrm{O}$ distanciamento social pode ser cruel quando não permite o encontro dos amigos e o refrescar da alma, pois o contato de forma virtual não permite abraços, que reiniciam a alma. Há que se permanecer atento aos sinais de cansaço mental, pois esse é muito mais preocupante que o físico.

\section{Palavras-chave}

Tecnologias. Professora. Distanciamento social. Mãe. Emoção.

Recebido em: 10/08/2020

Aprovado em: 22/12/2021

\section{Abstract}

This article is about the routine of a woman, who is also a mother, a teacher, and a student during social isolation and with the use of technology. In this time, some of these roles combine and one needs to overlap with another to make sure that the tasks are successfully done, but one role isn't more important than the others. All this brings emotions that need to be considered for the woman to maintain herself together and perform all of her roles. The social distancing can be cruel when it does not allow gathering with friends to renew the soul, this virtual way does not allow hugs that can do that. It is important to remain attentive to the signs of mental tiredness, as this can become more worrying than the body tiredness.

\footnotetext{
${ }^{1}$ Pedagoga formada na UEMG, pós-graduada em Educação Infantil e Alfabetização e Letramento pelo CEPEMG e em Tecnologias Digitais e Educação 3.0 pela UFMG.

E-mail: cislene.freitas@yahoo.com
} 
Pensei em começar esse texto de diversas maneiras, pois os papéis que eu desempenho são muitos e a pandemia faz ressaltar todos eles.Como estudante e amante das tecnologias, estou me divertindo, pois estou sendo obrigada a usar todos os meus conhecimentos e ainda procurar mais.

Como professora da educação básica, eu me sinto travada com meus conhecimentos, porque não consigo colocá-los em prática da maneira como gostaria.

Como mãe, me sinto esgotada, pois o acúmulo de tarefas e a preocupação com os filhos faz com que o trabalho não termine nunca.Como mulher, eu me vejo como uma borboleta que não consegue alcançar seus voos mais lindos. Assim os dias têm passado muito rápido, pois as demandas são intermináveis, porém nunca foram tão longos. O cansaço é mortal, físico e mental.

Estar em casa, com os filhos, é sim um privilégio. Não pude em nenhum outro momento fazer isso, então estou, na medida do possível, aproveitando cada momento. Fiz acampamento na sala, festa de aniversário para bicho de pelúcia entre outras atividades lúdicas. Mas isso somado a todos os afazeres domésticos e mais as atividades profissionais é uma demanda quase desumana.

O trabalho invadiu nossas casas, o nosso telefone e sendo assim muitas vezes não tem dia e nem hora para acontecer e muito menos para acabar. As demandas ficaram muito maiores, ou só foram realçadas?

O uso das tecnologias, que antes era devidamente evitado por falta de conhecimento e, por vezes, de vontade, se tornou imprescindível. Seja através de um aplicativo para pedir uma comida, quando você não tem mais fôlego para cozinhar ou para trabalhar. Mas não para por aí, para divertirmos baixamos o Tiktok e fazemos vídeos em família.

Na sala de aula, como professora, eu uso frequentemente vídeos, apresentações em Power Points, jogos on-line, entre outros recursos. Nos bastidores, para montar as aulas e deixá-las mais atrativas, uso o Canva, no qual faço pequenas 
animações e posts, o InShot, no qual edito vídeos e faço colagens e o Bitmoji,um aplicativo para a construção do avatar.

Nos momentos de estudo e também para comunicar, faço uso do Telegrama. Muitas informações chegam a todo momento. Talvez isso seja um dos motivos de esgotamento.

Quando reúno todas essas minhas partes à noite na hora de dormir, vem um misto de sentimentos. Às vezes me sinto realizada, por algo ter dado muito certo, às vezes me sinto culpada, por querer ter feito algo melhor tanto em relação ao trabalho, quanto em relação aos filhos, ou a mim mesma. Muitas vezes sou muito exigente comigo.

O isolamento social não está contribuindo muito para a leveza, pois me tirou uma das coisas que mais prezo, a companhia dos meus amigos. O abraço e aconchego, quando estou demandando demais de mim mesma.

Mas será que as tecnologias são apenas essas inovações tecnológicas? Segundo Kenski(2007,s.p.),“o conceito de tecnologias engloba a totalidade de coisas que a engenhosidade do cérebro humano conseguiu criar em todas as épocas, suas formas de uso, suas aplicações.”. Da mesma forma, a escrita é uma tecnologia, assim como as imagens. Quando a escrita foi inventada ajudou e muito a vida das pessoas, pois passou a registrar os conhecimentos.

Nós, professoras, usamos a escrita o tempo todo durante o distanciamento social, seja oficialmente nas aulas fazendo uma atividade, ou nas conversas nas redes sociais. Hoje a maioria das pessoas participa de uma rede social, como Whatsapp, Instagram, Facebook, ou como Twitter.

A contação de história é umas das tecnologias que mais faço uso nas minhas aulas. Me visto das personagens para dar a aula e só no final dela conto a história e falo para os alunos quem estou representando. Contar a história só no final, faz com que eles fiquem comigo até o término da aula, o que os deixam empolgados. Meus alunos também estão fazendo reconto, eu combino com eles 
antecipadamente qual personagem seremos e na hora da contação abrimos as câmeras e nos divertimos com os outros colegas.

A música é outra tecnologia que uso muito! Sempre começo minhas aulas cantando. Será que tem algum jeito melhor? Além da música e da contação de história, proponho brincadeiras e desafios. Tudo isso é tecnologia, pois tem a função de levar meus alunos de um lugar do conhecimento para outro.

Acredito que a melhor maneira de uma pessoa aprender, seja na escola, seja na vida é fazendo, se empenhando, buscando e com a ajuda das tecnologias esse processo fica mais leve e, por vezes, mais prazeroso.

"Na aprendizagem colaborativa, as tecnologias são ferramentas para execução para um projeto educacional maior, não sendo consideradas como um fim em si mesma." (SARTORI; ROESLER; FONTANA; BORGES, 2002, p. 36).

Em todos esses momentos, novas conexões estão sendo criadas; novos encontros de ideias são estabelecidos; e a aprendizagem efetiva é enfim realizada pela ação do próprio estudante, com o intermédio da tecnologia e a orientação do professor.

O meu papel é sobretudo de guiar, questionar, fazer o aluno ficar cada vez mais curioso e buscar seu próprio saber. Mas tudo isso se dá em uma situação em que a internet é instável; plataforma que às vezes não está acessível; o computador que não tem memória e processamento suficiente para lidar com tantos arquivos e funcionalidades abertas simultaneamente.

E isso pesa também a alma, o coração fica angustiado e desesperado frente da máquina que não funciona da maneira que você e as crianças gostariam e, muitas vezes, pais que estão te esperando.

Mas nós, mulheres, estamos de alguma forma sendo mais afetas com a pandemia? Eu particularmente, acredito que sim. Especialmente, aquelas que 
são mães de crianças pequenas, pois nos dividir entre o trabalho oficial, o trabalho de casa e trabalho com os pequenos é muito estressante.

Muitas são mães solo, estão na luta diária sem a figura paterna e precisam seguir sem o apoio que deveria vir mesmo sendo mãe solo. $O$ pai que restringe $o$ seu papel a visitas quinzenais muito pouco sabe e quer saber do que acontece de verdade. Existe ainda aquelas que os pais não reconheceram ou já não estão mais aqui. E porque não dizer dos pais que mesmo estando no mesmo teto delegam tudo para as mães? Essa conta raramente fecha. A que se debater muito sobre isso e parar de romantizar as mães guerreiras.

Sem uma ajuda profissional, é praticante impossível sair ileso disso tudo. Fazer terapia é um alívio para a alma e ajuda a conectar as ideias, fazer as pontes que por vezes ficam desconectadas.

Muitas de nós praticam atividades físicas, o que, nesse momento, também não é possível fazer com tanta facilidade quanto antes. São muitas as adaptações que devemos e temos que fazer para ficar bem e deixar todos os outros que dependem de nós bem.

Qual é o peso disso? Às vezes não é possível sentir nossa própria dor, pois há muito o que se fazer. As cobranças são muitas e veem de todos os lados, família, trabalho, alunos, filhos.

Sou professora com muito prazer, professora em duas escolas, duas realidades diferentes, inúmeras demandas. Atividades, aulas, notas, vídeo, reunião, formação, diário, faltas. Esse ano terá fim? Ou eu terei?Acredito de verdade que o ano terá um fim, o melhor que pudermos construir, pois eu dou o meu melhor a cada dia.

Os dias no distanciamento social são regados a tecnologias, sejam elas digitais ou não, mas não há tecnologia capaz de superar o poder do encontro olho no olho e do aconchego do abraço presencial. 


\section{Referências}

KENSKI, Vani Moreira. Educação e tecnologias: O novo ritmo da informação.

Campinas. $\quad$ SP: Papirus, 2007 Disponível em:

https://books.google.com.br/books/about/Educa\%C3\%A7\%C3\%A30_E_Tecno logias.html?id=ncTG4eloSkoC\&source=kp_book_description\&redir_esc=y.

Acesso em: 6 de agosto de 2020.

SARTORI, Ademilde Silveira; ROESLER, Jucimara; FONTANA, Klater Bez; BORGES, Martha Kaschny. Tecnologia, Educação e aprendizagem: os desafios para o educador na era da comunicação e da informação. Florianópolis: UESC, 2002. 